\title{
The degree of equity and coupling coordination of staff in primary medical and health care institutions in China 2013-2019
}

Weicun Ren ${ }^{1,2}$, Clifford Silver Tarimo ${ }^{1,3}$, Lei Sun², Zihan $\mathrm{Mu}^{1}$, Qian $\mathrm{Ma}^{2}$, Jian Wu and Yudong Miao ${ }^{1 *}$

\begin{abstract}
Background: Primary medical and health care facilities are the first lines of defense for the health of population. This study aims to evaluate the current state and trend of equity and coupling coordination degree (CCD) of staff in primary medical and health care institutions (SPMHCI) based on the quantity and living standards of citizens in China 2013-2019. The research findings are expected to serve as a guideline for the allocation of SPMHCI.

Methods: The data used in this study including the quantity and living standards of citizens, as well as the number of SPMHCl in 31 provincial administrative regions of China, were obtained from the China Statistical Yearbook and the China Health Statistics Yearbook. The equity and CCD for SPMHCI were analyzed by using the Gini coefficient and the CCD model, and the Grey forecasting model GM $(1,1)(G M)$ was used to predict the equity and CCD from 2020 to 2022.

Results: Between 2013 and 2019, the number of SPMHCl increased from 3.17 million to 3.50 million, and the population-based Gini coefficient declined from 0.0704 to 0.0513 . In urban and rural areas, the Gini coefficients decreased from 0.1185 and 0.0737 to 0.1025 and 0.0611 , respectively. The CCD between SPMHCl and citizens' living standards (CLS) changed from $0.5691,0.5813,0.5818$ to $0.5650,0.5634,0.6088$ at national, urban, and rural levels, respectively. The forecasting results of GM revealed that at the national, urban and rural levels from 2020 to 2022, the Gini coefficient would rise at a rate of $-13.53,-5.77 \%$, and $-6.10 \%$, respectively, while the CCD would grow at a rate of -0.89 , 1.06 , and $0.87 \%$, respectively.

Conclusions: In China, the number of SPMHCI has increased significantly, with an equitable allocation based on the population. The interaction between SPMHCl and CLS is sufficient, but the degree of mutual promotion is moderate. The government could optimize $\mathrm{SPMHCl}$ and improve the chronic disease management services to improve CLS and to ensure the continued operation of primary medical and health care institutions in urban areas.
\end{abstract}

Keywords: Primary medical and health care institutions, Equity, Coupling coordination degree, Medical staff, GM (1, 1)

*Correspondence: meldon@zzu.edu.cn

${ }^{1}$ College of Public Health, Zhengzhou University, 100, Science Avenue, Gaoxin District, Zhengzhou 450001, Henan, China

Full list of author information is available at the end of the article

\section{Introduction}

Primary health care is gaining popularity worldwide since everyone has the right to receive basic health care $[1,2]$. Primary medical and health care institutions have gradually evolved into the guardians of people's health, assuming the functions of first diagnosis, referral, chronic disease management, health education, and post-ill rehabilitation as the hierarchical diagnosis and treatment 
system has advanced [3, 4]. Human resources for health are a critical component of the development of medical and health care services. As the foundation of the entire medical and health care service system, the development and innovation of primary medical and health care institution determines the quality of primary medical work including diagnosis, treatment, as well as the levels of all basic public health services $[5,6]$. In China, the "Healthy China 2030" initiative proposed in 2016 emphasizes that it is necessary to strengthen the grass-roots talent team and increase support for the grass-roots and remote areas [7]. In addition, Guiding Opinions on Further Regulating Community Health Service Management and Improving Service Quality put forward more specific guidelines for the development of health manpower in primary medical and health care institutions [8].

Aging population [9], chronic noncommunicable diseases [10], and total health expenditure [11] are all on the rise, and the role of primary medical and health care institutions is becoming increasingly important. However, the number of primary medical and health care institutions in China in 2019 was 687,731, accounting for $68.26 \%$ of all medical institutions. Among them, the number of institutions in urban and rural areas are 35,013 and 652,718, respectively [12]. The staff in primary medical and health care institutions (SPMHCI) is 25.07 per 10,000 citizens [13]. Simultaneously, the SPMHCI continues to face challenges that affect the sustainable development of primary medical and health institutions, including significant losses, unscientific management, irrational organizational structures, and low levels of academic qualifications and professional titles [14]. Therefore, as one of the important factors that affect the management and development of primary medical and health institutions, the equitable and coordinated allocation of human resources deserves special consideration [1].

Studies on the equitable of SPMHCI have provided critical evidence for optimizing resource distribution. Researchers employ a variety of techniques to analyze and assess the equity of staffing in diverse regions and institutions. Efrat $\mathrm{S}$ et al. analyzed the role of equity in the allocation of SPMHCI providing preventive services [15]. The study discovered that the distribution of general practitioners in Australia was skewed using the Robin Hood Index [16]. Sun WX discovered that, in terms of Gini coefficient, the primary medical and health institutions in Jilin province in China allocated the health resources more efficiently by population than by geographic area [17]. In addition, Lin CM found that the inequity for the allocation of general practitioners between districts and counties in Beijing had been increasing year by year in terms of maximum/minimum value (multiples), relative difference coefficient, Gini coefficient, and difference index [18].

The coordination between SPMHCI and the health demands of citizens determines the efficiency and effectiveness of their work [19]. Citizens' health demands are closely related to their standard of living [20]. Miller Fiona $\mathrm{A}$ et al. proposed four regulatory coordination models such as health technology assessment organizations and group procurement organizations by using the methods of document review and key informant interviews [21]. Okech $\mathrm{M}$ et al. discovered that human resources for health coordination platforms with strong governance structures are sustainable [19], while Wang W examined the interaction between investment in medical staff and urbanization in China from 1995 to 2015 and found that the two systems were in a convergence trend but still show a low coupling strength and a low level of coordination [22]. Zhang $\mathrm{C}$ used the entropy weight-set pair analysis model to quantify and evaluate the basic public services and economic development in 16 cities in Anhui Province from 2009 to 2018, revealing a lack of overall coordination between the two [23].

As previously stated, existing research on the equity of SPMHCI is primarily focused on regions classified by administration, economy, and geographic location, with relatively little comparative analysis between urban and rural primary medical and health institutions [3-5]. Additionally, prior research on the relationship between SPMHCI and other facets of society has tended to focus on institutional and economic dimensions, with little attention paid to the level of citizens' living standards (CLS). We think that it is necessary to adjust and optimize the allocation of SPMHCI in a timely manner in order to promote social equity and meeting the needs of the people. Thus, this study examined the current state, equity, coupling degree and coupling coordination degree (CCD) of SPMHCI in China from 2013 to 2019. The Gini coefficient was used to analyze the equity of SPMHCI based on the population. In addition, the CCD model was used to evaluate the coupling degree and CCD between SPMHCI and CLS at national, urban, and rural levels. Finally, the number, equity, and CCD of SPMHCI in China from 2020 to 2022 were predicted by using the Grey forecasting model GM $(1,1)$ (GM) in order to further explore the future development of SPMHCI. Findings of the current study are expected to serve as a guide for the government to optimize the allocation of SPMHCI.

\section{Materials and methods Data sources}

The data for this study come from 31 provincial-level administrative regions in China, which include 22 
provinces, five autonomous regions (Inner Mongolia, Guangxi, Tibet, Ningxia, and Xinjiang), and four municipalities (Beijing, Tianjin, Shanghai, and Chongqing). The China Statistical Yearbook provided information on the quantity of citizens and CLS in each region (2014-2020) [24] while data on the number of SPMHCI was obtained from the China Health Statistical Yearbook (2014-2020) [12, 25-30], and the total sample size is 217. Among them, CLS information includes information on per capita disposable income and per capita consumption expenditure, and SPMHCI refers to the total number of staff in primary medical and health care institutions, including doctors, nurses, management personnel, medical technicians, logistical personnel and others. In this study, primary medical and health care institutions refer to community health service centers and stations in urban areas, as well as township health centers and village clinics in rural areas. The eastern region, central region, and western region of China were defined according to the China Health Statistics Yearbook 2020.

\section{Data analysis \\ Gini coefficient}

The Gini coefficient was proposed by Corrado Gini in 1912, which indicates the income distribution of a country or region and the equity of social wealth distribution [31]. It can also be used to assess the equity of public resource allocation. At the moment, methods for calculating the Gini coefficient are quite developed. Besides the most frequently used method with regional groups based on the Lorentz curve's interpretation, there are methods using covariance and square difference [32]. Among them, the square difference method is used to analyze data in which the research object cannot be grouped evenly and is less grouped [32]. Given that the data are based on a single province, the population cannot be divided equally into groups, and thus the regional grouping method is not applicable. The covariance method is more accurate for calculations involving a larger number of groups, but China's provincial administrative regions are relatively few in number. According to the applicability of the methods, this study calculates the Gini coefficient for SPMHCI based on the quantity of citizens using square difference method. In this study, 22 provinces, 5 autonomous regions, and 4 municipalities were ranked based on the number of SPMHCI. The formula for calculating the national and regional Gini coefficients using average difference is:

$$
\mathrm{G}=1-\sum_{\mathrm{i}=1}^{\mathrm{n}} \mathrm{P}_{\mathrm{i}}\left(2 \mathrm{Q}_{\mathrm{i}}-\mathrm{W}_{\mathrm{i}}\right)
$$

$$
Q_{i}=\sum_{i=1}^{n} W_{i}
$$

Among them, " $\mathrm{n}$ " represents the number of groups; $\mathrm{W}_{\mathrm{i}}$ represents the ratio of the number of SPMHCI in the $i$-th group to that of the total in the country; $P_{i}$ denotes the ratio of the quantity of citizens in the $i$-th group to that of the total population; $Q_{i}$ indicates the cumulative percentage of $\mathrm{W}_{\mathrm{i}}$ from group 1 to group $\mathrm{i}$; the sum of $\mathrm{W}_{\mathrm{i}}$ and $\mathrm{P}_{\mathrm{i}}$ for all groups are both $1(i=1,2,3, \ldots, n)$.

The value of the Gini coefficient is between 0 and 1 , and the smaller the value, the higher the equity of SPMHCI [33].

\section{Coupling coordination degree model}

The role of coupling degree model is to quantify the degree of interaction between systems or various elements within them, indicating whether the movement among elements can achieve benign interactions of two or more parties [34]. Coordination degree aims at quantifying the degree of multi-party cooperation between systems or various elements within the system in a certain development stage. This study analyzed the CCD between SPMHCI and CLS systems to indicate whether the movement trend among two systems can form a law of pulling growth in the same direction during the development process [35]. The formula for calculating the coupling degree between the two systems is as follows:

$$
\begin{gathered}
y_{1 i}=\frac{x_{1 i}-x_{1 \min }}{x_{1 \max }-x_{1 \min }}, \quad y_{2 i}=\frac{x_{2 i}-x_{2 \min }}{x_{2 \max }-x_{2 \min }}, \quad y_{3 i}=\frac{x_{3 \max }-x_{3 i}}{x_{3 \max }-x_{3 \min }} \\
d_{j}=1+\frac{\sum_{i=1}^{31} y_{j i} \ln y_{j i}}{\ln 31}, \quad w_{j}=\frac{d_{j}}{\sum_{j=1}^{3} d_{j}} \\
\mathrm{U}_{1}=\frac{\sum_{i=1}^{31} y_{1 i}}{31}, U_{2}=\frac{\sum_{i=1}^{31} y_{2 i}}{31} * \frac{w_{2}}{w_{2}+w_{3}}+\frac{\sum_{i=1}^{31} y_{3 i}}{31} * \frac{w_{3}}{w_{2}+w_{3}} \\
\mathrm{C}=\frac{\sqrt{\mathrm{U}_{1} \mathrm{U}_{2}}}{\frac{\mathrm{U}_{1}+\mathrm{U}_{2}}{2}}
\end{gathered}
$$

Among them, $\mathrm{y}_{1 \mathrm{i}}, \mathrm{y}_{2 \mathrm{i}}, \mathrm{y}_{3 \mathrm{i}}, \mathrm{x}_{1 \mathrm{i}}, \mathrm{x}_{2 \mathrm{i}}, \mathrm{x}_{3 \mathrm{i}}, \mathrm{x}_{1 \max }, \mathrm{x}_{2 \max }, \mathrm{x}_{3 \max }$, $\mathrm{x}_{1 \min }, \mathrm{x}_{2 \min }, \mathrm{x}_{3 \min }$ represent the standardized, original, maximum and minimum values of SPMHCI, per capita disposable income and per capita consumption expenditure, respectively (i $=1,2,3, \ldots, 31) ; d_{j}$ and $w_{j}$ respectively represent the information utility value and weight of SPMHCI, 
per capita disposable income and per capita consumption expenditure $(j=1,2,3)$. $U_{1}$ and $U_{2}$ denote the comprehensive evaluation value of SPMHCI and CLS, respectively. C is the coupling degree between the two systems, $C \in[0,1]$. The closer the $C$ value is to 1 , the more coupling the development of the two systems.

The degree of coupling only reflects the degree of interaction between the systems, not the level of each system [36]. The CCD can not only reflect whether each system has a good level, but also reflect the degree of mutual promotion between systems [35]. To understand the CCD between SPMHCI and CLS, a model is established:

$$
\begin{aligned}
& \mathrm{D}=\sqrt{\mathrm{C} \times \mathrm{T}} \\
& \mathrm{T}=\mathrm{w}_{1} \mathrm{U}_{1}+\left(\mathrm{w}_{2}+\mathrm{w}_{3}\right) \mathrm{U}_{2}
\end{aligned}
$$

Where " $\mathrm{D}$ " denotes the $\mathrm{CCD}$; " $\mathrm{C}$ " indicates the coupling degree; "T" denotes the total evaluation value of SPMHCI and CLS.

This study referred to the study conducted by Wang RX [32] and categorized the CCD of SPMHCI and CLS into 6 levels. The CCD value less than 0.5 indicates that SPMHCI and CLS are uncoordinated while the value between 0.5 and $0.6,0.6$ and $0.7,0.7$ and 0.8 indicates edge coordination, preliminary coordination and intermediate coordination, respectively. CCD value between $0.8-0.9$ indicates good coordination while values between $0.9-1.0$ indicates highquality coordination.

\section{Grey forecasting model GM $(1,1)$}

Grey system theory believes that even an irregular discrete time-space sequence has potential orderliness, which can become a regular sequence that satisfies the grey system theoretical modeling conditions [37]. The use of grey system theory for prediction has the advantages of high accuracy, fewer sample data and simple calculation principle and method. Grey system theory includes four types of models: GM $(1,1)$, DGM $(1,1), \mathrm{GM}(1, \mathrm{~N})$ and Verhulst. The commonly used one is the GM $(1,1)$ model, which represents a first-order, one-variable prediction model.

Firstly, create an original data column based on the number, equity and CCD data of SPMHCI in China from 2013 to 2019 followed by generating a cumulative sequence based on the original data column. We then tested the quasi-smoothness and quasi-exponential law of the cumulative sequence and finally applied the least square method to solve the model parameters $(\mathrm{a}, \mathrm{u})$ based on the cumulative sequence [38]. The final predictive model available is:

$$
x^{(1)}(i+1)=\left[x^{(1)}(1)-\frac{u}{a}\right] e^{-a u}+\frac{u}{a}
$$

Where $x^{(1)}(i)$ represents the $i$-th number in a cumulative sequence $(i=1,2,3, \ldots, 7)$ and $e$ is the natural index while $\mathrm{a}, \mathrm{u}$ are parameters.

\section{Analysis tool}

The initial data was collected and processed by using Excel 2019 software. Excel 2019 software was also used to perform Gini coefficient and CCD analysis. GM was performed by using Matlab 2014 software. $P<0.05$ was considered statistically significant.

\section{Results}

This study analyzed the trend, equity, and CCD for SPMHCI from 2013 to 2019 at the national, urban, and rural levels. The analyzed parameters include the Gini coefficient and CCD. The GM was applied to predict the trend, equity, and CCD from 2020 to 2022.

\section{The basic situation of SPMHCl in China from 2013 to 2019}

In China, the number of SPMHCI increased from 3.17 million in 2013 to 3.50 million in 2019, at an average annual rate of $1.76 \%$. At the end of 2019 , the population of China was 1.397 billion. In terms of CLS, average annual growth rates for per capita disposable income and consumption expenditure were 11.31 and $10.51 \%$, respectively. Table 1 and Appendix Table show the detailed information.

\section{The equity for the allocation of SPMHCI}

From 2013 to 2019, the population-based Gini coefficient of SPMHCI dropped from 0.0704 to 0.0513 , with a rate of change of $-27.13 \%$. In addition, the Gini coefficients of SPMHCI at urban and rural levels were all lower than 0.1207 from 2013 to 2019, and the rate of change was $-13.50 \%$ and $-17.10 \%$, respectively. The results also revealed that in China, the allocation of SPMHCI in rural areas was more equitable than that in urban areas. See Table 2.

\section{The CCD between SPMHCl and CLS}

The weighted analysis based on the entropy method found that the change rates of indicator weights of CLS and SPMHCI from 2013 to 2019 were -19.01 and $17.87 \%$, respectively. Specific to urban and rural areas, the weights of SPMHCI and CLS were 0.3985-0.3055 and 0.6015-0.6945 in urban areas; in rural areas, the weights of SPMHCI and CLS were 0.4014-0.4942 and 0.5058-0.5986, respectively.

Coordination between SPMHCI and CLS in the national, urban, and rural areas were 0.9957-0.9999, 0.9951-0.9999, and 0.9886-0.9999, respectively. The 
Table 1 The baseline situation of Chinese citizens and SPMHCI from 2013 to 2019

\begin{tabular}{|c|c|c|c|c|c|c|c|c|}
\hline Index & 2013 & 2014 & 2015 & 2016 & 2017 & 2018 & 2019 & $\begin{array}{l}\text { Average } \\
\text { growth rate } \\
\text { (\%) }\end{array}$ \\
\hline \multicolumn{9}{|l|}{ SPMHCla $(10,000$ people) } \\
\hline Country & 316.72 & 319.65 & 320.02 & 327.86 & 336.99 & 341.52 & 350.09 & 1.76 \\
\hline Urban & 47.61 & 48.88 & 50.48 & 52.20 & 55.47 & 58.29 & 61.03 & 4.70 \\
\hline Rural & 269.11 & 270.77 & 269.54 & 275.66 & 281.52 & 283.23 & 289.06 & 1.24 \\
\hline \multicolumn{9}{|l|}{$\mathrm{CLS}^{\mathrm{b}}$ in national areas (yuan) } \\
\hline Per capita disposable income & $18,310.8$ & $20,167.1$ & $21,966.2$ & $23,821.0$ & $25,973.8$ & $28,228.0$ & $30,732.8$ & 11.31 \\
\hline Per capita consumption expenditure & $13,220.4$ & $14,491.4$ & $15,712.4$ & $17,110.7$ & $18,322.1$ & $19,853.1$ & $21,558.9$ & 10.51 \\
\hline \multicolumn{9}{|l|}{ CLS in urban areas (yuan) } \\
\hline Per capita disposable income & $26,955.1$ & $28,843.9$ & $31,194.8$ & $33,616.2$ & $12,363.4$ & $36,396.2$ & $42,358.8$ & 9.52 \\
\hline Per capita consumption expenditure & $18,022.6$ & $19,968.1$ & $21,392.4$ & $23,078.9$ & $10,129.8$ & $24,445.0$ & $28,063.4$ & 9.29 \\
\hline \multicolumn{9}{|l|}{ CLS in rural areas (yuan) } \\
\hline Per capita disposable income & 9429.6 & $10,488.9$ & $11,421.7$ & $12,363.4$ & $13,432.4$ & $14,617.0$ & $16,020.7$ & 11.65 \\
\hline Per capita consumption expenditure & 6625.5 & 8382.6 & 9222.6 & $10,129.8$ & $10,954.5$ & $12,124.3$ & $13,327.7$ & 16.68 \\
\hline \multicolumn{9}{|l|}{ Citizens $^{c}(10,000$ people) } \\
\hline Country & 134,792 & 135,514 & 136,249 & 137,088 & 137,982 & 138,834 & 139,656 & 0.60 \\
\hline Urban & 71,626 & 73,492 & 75,385 & 77,517 & 79,791 & 81,972 & 83,946 & 2.87 \\
\hline Rural & 63,166 & 62,022 & 60,864 & 59,571 & 58,191 & 56,862 & 55,710 & -1.97 \\
\hline
\end{tabular}

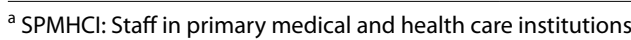

${ }^{\mathrm{b}} \mathrm{CLS}$ : Citizens' living standards

'Citizens: Number of citizens at the end of the year

Table 2 Gini Coefficient for allocation of SPMHCla in China from 2013 to 2019

\begin{tabular}{lllllllll}
\hline Variable & $\mathbf{2 0 1 3}$ & $\mathbf{2 0 1 4}$ & $\mathbf{2 0 1 5}$ & $\mathbf{2 0 1 6}$ & $\mathbf{2 0 1 7}$ & $\mathbf{2 0 1 8}$ & $\mathbf{2 0 1 9}$ & Growth rate (\%) \\
\hline National & 0.0704 & 0.0687 & 0.0646 & 0.0552 & 0.0515 & 0.0487 & 0.0513 & -27.13 \\
Urban & 0.1185 & 0.1207 & 0.1203 & 0.1156 & 0.1102 & 0.1128 & 0.1025 & -13.50 \\
Rural & 0.0737 & 0.0696 & 0.0688 & 0.0615 & 0.0594 & 0.0604 & 0.0611 & -17.10 \\
\hline
\end{tabular}

${ }^{a}$ SPMHCI: Staff in primary medical and health care institutions

growth rate of coupling degree was negative only in urban areas $(-0.08 \%)$. On the other hand, the national level CCD between SPMHCI and CLS from 2013 to 2019 were $0.5642-0.5775$, and the maximum CCD in urban and rural areas were 0.5813 and 0.6088 , respectively. Only in rural areas did CCD grow at a positive rate (4.64\%), which was much higher than the growth rate of $\mathrm{CCD}$ at the national and urban areas. For more details, see Table 3 .

\section{Forecast of the equity and CCD of SPMHCI from 2020 to 2022}

Based on the equity and CCD data of SPMHCI from 2013 to 2019, this study applies GM to forecast of the equity and CCD from 2020 to 2022, and the model fits well with all the variance ratio (VR) less than 0.5. The GM analysis found that population-based Gini coefficients of SPMHCI in 2020, 2021 and 2022 would be 0.0436, 0.0406 and 0.0377 , respectively. And the Gini coefficients at urban and rural levels would be 0.1023, 0.0993, 0.0964 and 0.0566, 0.0548, 0.0531, respectively. Between 2020 and 2022, the CCD between SPMHCI and LSR would predict a value of $0.5577-0.5625$, with a growth rate of $-0.89 \%$. The growth rates for urban and rural areas are projected to be 1.06 and $0.87 \%$, respectively. See Table 4 , Fig. 1 and Fig. 2.

In addition, we also forecast the number of SPMHCI in China from 2020 to 2022. The predictive analysis results of the GM found that the number of SPMHCI in urban and rural areas in 2020, 2021 and 2022 are projected to be $637,270,667,420,698,990$ and 2,924,200, $2966,200,3,008,700$, respectively. The rate of change would be 9.69 and $2.89 \%$. More details are displayed in Table 5. 
Table 3 The CCD ${ }^{a}$ between SPMHCl ${ }^{b}$ and CLS $^{c}$ in China from 2013 to 2019

\begin{tabular}{|c|c|c|c|c|c|c|c|c|}
\hline Variable & 2013 & 2014 & 2015 & 2016 & 2017 & 2018 & 2019 & Growth rate (\%) \\
\hline \multicolumn{9}{|l|}{ Weight } \\
\hline \multicolumn{9}{|l|}{ National } \\
\hline SPMHCI & 0.4846 & 0.4617 & 0.4378 & 0.4277 & 0.4069 & 0.3986 & 0.3925 & -19.01 \\
\hline CLS & 0.5154 & 0.5383 & 0.5622 & 0.5723 & 0.5931 & 0.6014 & 0.6075 & 17.87 \\
\hline \multicolumn{9}{|l|}{ Urban } \\
\hline SPMHCl & 0.3843 & 0.3199 & 0.3174 & 0.3055 & 0.3985 & 0.3235 & 0.3470 & -9.71 \\
\hline CLS & 0.6157 & 0.6801 & 0.6826 & 0.6945 & 0.6015 & 0.6765 & 0.6530 & 6.06 \\
\hline \multicolumn{9}{|l|}{ Rural } \\
\hline SPMHCI & 0.4942 & 0.4577 & 0.4511 & 0.4462 & 0.4565 & 0.4014 & 0.4701 & -4.88 \\
\hline $\mathrm{CLS}$ & 0.5058 & 0.5423 & 0.5489 & 0.5538 & 0.5435 & 0.5986 & 0.5299 & 4.76 \\
\hline \multicolumn{9}{|c|}{ Coupling degree } \\
\hline National & 0.9957 & 0.9977 & 0.9991 & 0.9999 & 0.9995 & 0.9981 & 0.9977 & 0.20 \\
\hline Urban & 0.9999 & 0.9963 & 0.9976 & 0.9957 & 0.9951 & 0.9977 & 0.9991 & -0.08 \\
\hline Rural & 0.9886 & 0.9895 & 0.9915 & 0.9932 & 0.9947 & 0.9999 & 0.9971 & 0.86 \\
\hline \multicolumn{9}{|l|}{ CCD } \\
\hline National & 0.5691 & 0.5748 & 0.5755 & 0.5775 & 0.5712 & 0.5642 & 0.5650 & -0.72 \\
\hline Urban & 0.5813 & 0.5434 & 0.5455 & 0.5359 & 0.5392 & 0.5443 & 0.5634 & -3.08 \\
\hline Rural & 0.5818 & 0.5953 & 0.5988 & 0.6015 & 0.6000 & 0.6075 & 0.6088 & 4.64 \\
\hline
\end{tabular}

${ }^{a}$ CCD: Coupling coordination degree

b SPMHCI: Staff in primary medical and health care institutions

${ }^{c} \mathrm{CLS}$ : Citizens' living standards

Table 4 Prediction of the equity and $\mathrm{CCD}^{\mathrm{a}}$ of $\mathrm{SPMHCl}^{\mathrm{b}}$ in China from 2020 to 2022

\begin{tabular}{|c|c|c|c|c|c|}
\hline Variable & 2020 & 2021 & 2022 & Growth rate (\%) & Variance ratio \\
\hline \multicolumn{6}{|c|}{ Gini Coefficient } \\
\hline National & 0.0436 & 0.0406 & 0.0377 & -13.53 & 0.3019 \\
\hline Urban & 0.1023 & 0.0993 & 0.0964 & -5.77 & 0.3663 \\
\hline Rural & 0.0566 & 0.0548 & 0.0531 & -6.18 & 0.3973 \\
\hline \multicolumn{6}{|l|}{ CCD } \\
\hline National & 0.5625 & 0.5599 & 0.5575 & -0.89 & 0.5258 \\
\hline Urban & 0.5554 & 0.5584 & 0.5613 & 1.06 & 0.4475 \\
\hline Rural & 0.6113 & 0.6139 & 0.6166 & 0.87 & 0.1737 \\
\hline
\end{tabular}

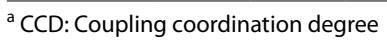

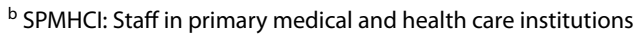

\section{Discussion}

This study aimed to evaluate the equity and coordination of SPMHCI by analyzing the population-based Gini coefficient and the CCD between CLS in China. The findings show that while the number of SPMHCI has increased significantly in China, it is still insufficient. The population-based Gini coefficient and the coupling degree between CLS were impressive, but the CCD between CLS was somewhat moderate.

Specifically, The Gini coefficient for the allocation of SPMHCI in China dropped from 0.0704 in 2013 to
0.0513 in 2019, which is a more equitable value. China's SPMHCI allocation plan is mainly based on the standard of health resources per 10,000 population, which is equal in population-based allocation and has shown a more equitable development trend in recent years. However, the Gini coefficient at urban and rural levels from 2013 to 2019 decreased from $0.1185,0.0737$ to 0.1025 , 0.0611 , respectively. It shows that the equity of SPMHCI at national level is better than those at rural and urban levels. This is consistent with the research results of Kong Y [39] and Liu ZY et al. [40]. The prediction results based on GM are as well consistent with this conclusion.

In comparison to national equity, the poor equity score calculated at the urban and rural levels may be related to the dispersed lifestyles of rural residents in western China, which is why the government has increased the number of SPMHCI to ensure residents have access to basic medical services. At the same time, urban areas pay less attention to SPMHCI than rural areas do, owing to increased allocation of medical resources and availability of choices [41]. However, with the improvement of population aging and the increase of chronic disease patients, the government and heads of urban primary medical and health care institutions should pay greater attention to the allocation of SPMHCI to provide better health guidance, rehabilitation, and nursing services to community citizens. 


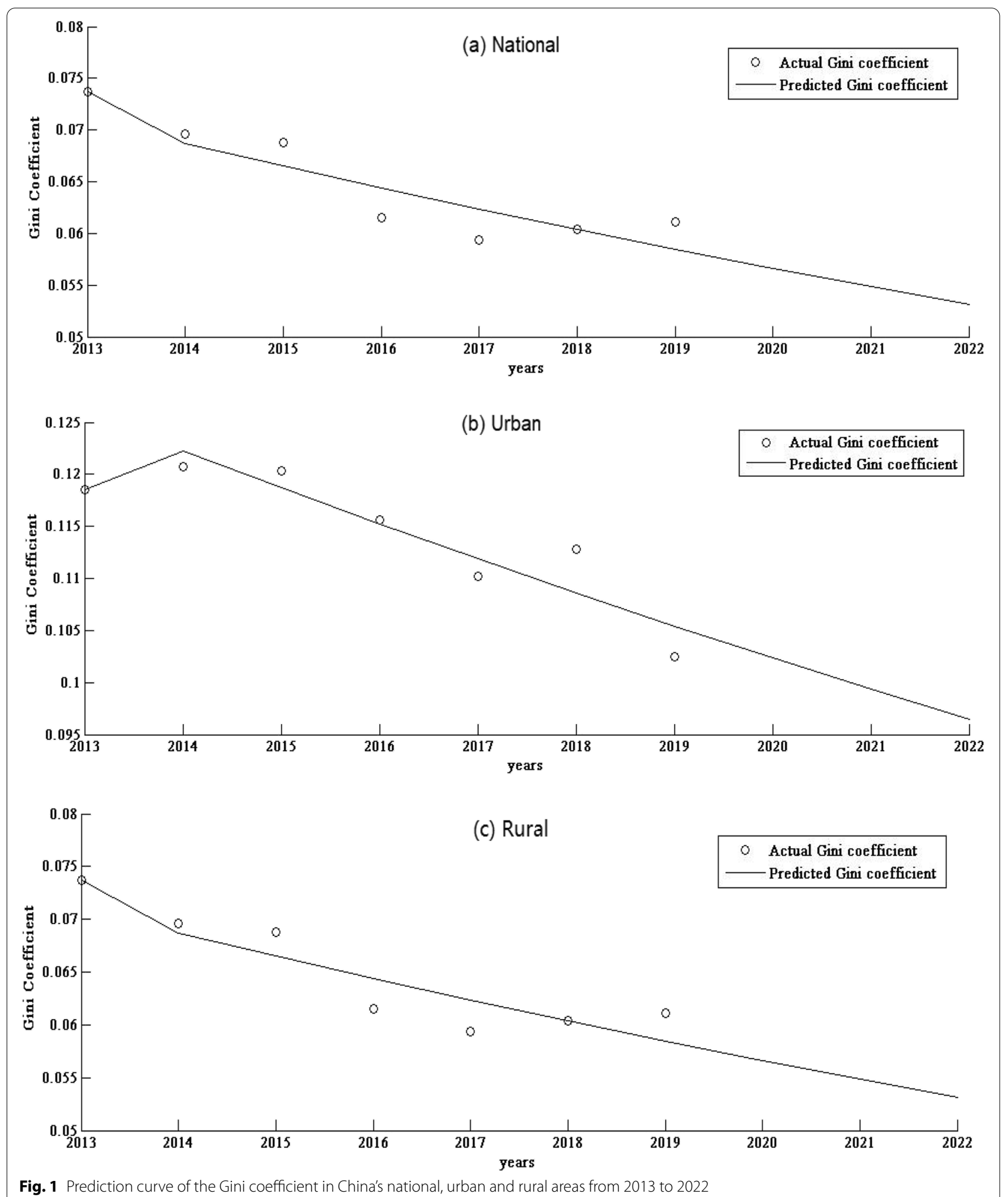

Fig. 1 Prediction curve of the Gini coefficient in China's national, urban and rural areas from 2013 to 2022 

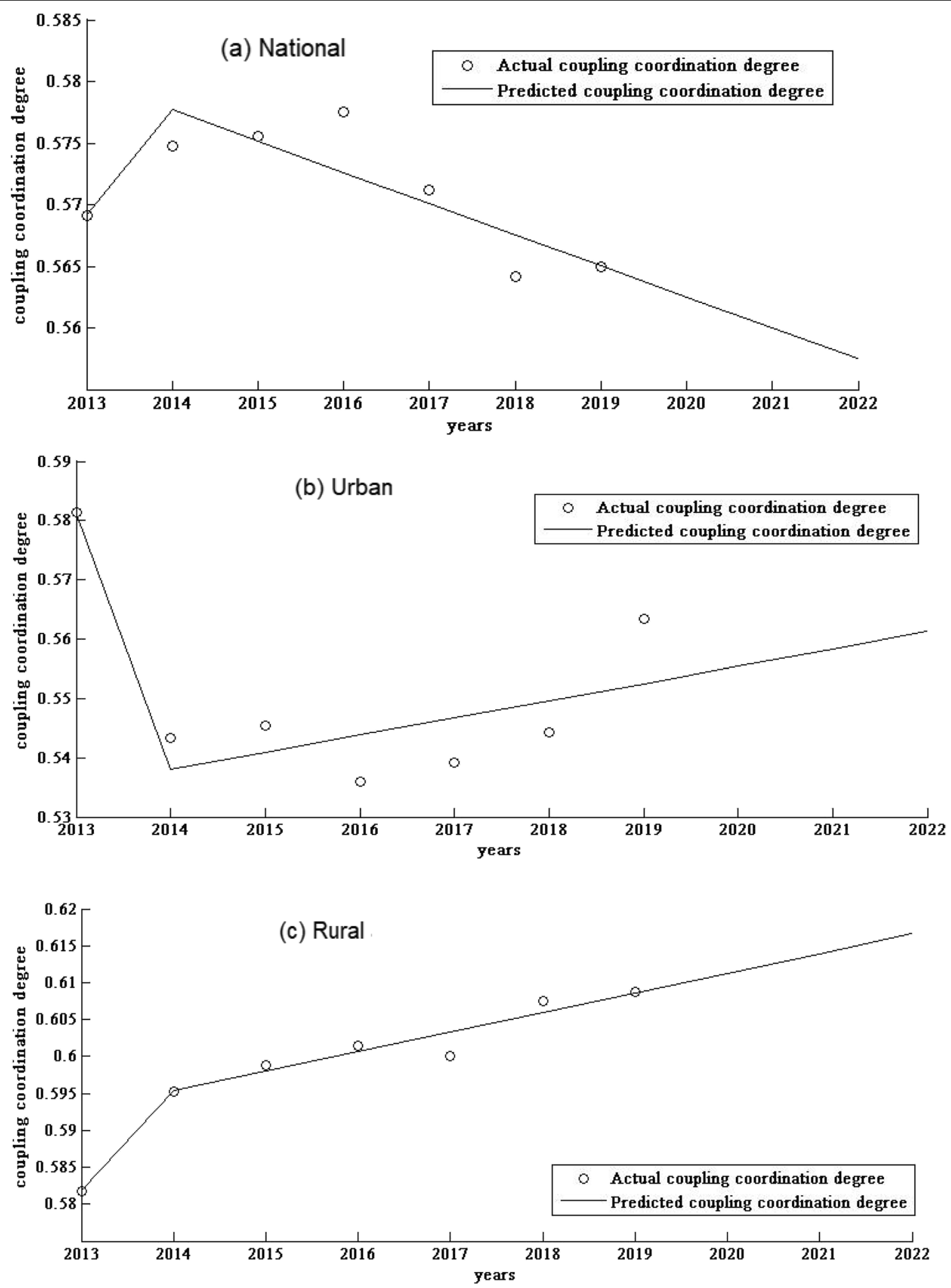

Fig. 2 Prediction curve of the coupling coordination degree in China's national, urban and rural areas from 2013 to 2022 
Table 5 Prediction of SPMHCl ${ }^{\mathrm{a}}$ in China's urban and rural areas from 2020 to 2022 (people)

\begin{tabular}{|c|c|c|c|c|c|c|c|c|}
\hline \multirow[t]{2}{*}{ Area } & \multicolumn{2}{|l|}{2020} & \multicolumn{2}{|l|}{2021} & \multicolumn{2}{|l|}{2022} & \multicolumn{2}{|c|}{ Growth rate (\%) } \\
\hline & Urban & Rural & Urban & Rural & Urban & Rural & Urban & Rural \\
\hline Total & 637,270 & $2,924,200$ & 667,420 & $2,966,200$ & 698,990 & $3,008,700$ & 9.69 & 2.89 \\
\hline Eastern region ${ }^{b}$ & 359,280 & $1,012,600$ & 375,620 & $1,024,200$ & 392,700 & $1,036,000$ & 9.30 & 2.31 \\
\hline Middle regionc & 145,300 & $1,002,300$ & 150,370 & $1,008,100$ & 155,610 & $1,013,900$ & 7.10 & 1.16 \\
\hline Western region ${ }^{d}$ & 133,000 & 905,810 & 142,040 & 928,230 & 151,700 & 951,200 & 14.06 & 5.01 \\
\hline Beijing & 41,114 & 4524 & 43,313 & 4494 & 45,629 & 4464 & 10.98 & -1.33 \\
\hline Tianjin & 10,683 & 13,016 & 11,304 & 13,209 & 11,960 & 13,405 & 11.95 & 2.99 \\
\hline Hebei & 20,460 & 178,990 & 21,491 & 180,390 & 22,573 & 181,810 & 10.33 & 1.58 \\
\hline Shanxi & 14,059 & 80,159 & 14,489 & 81,102 & 14,931 & 82,056 & 6.20 & 2.37 \\
\hline Inner Mongolia & 14,798 & 53,491 & 15,431 & 54,710 & 16,091 & 55,957 & 8.74 & 4.61 \\
\hline Liaoning & 20,506 & 59,297 & 21,514 & 59,672 & 22,571 & 60,051 & 10.07 & 1.27 \\
\hline Jilin & 10,047 & 45,289 & 10,356 & 44,656 & 10,674 & 44,032 & 6.24 & -2.78 \\
\hline Heilongjiang & 14,700 & 54,370 & 14,562 & 54,061 & 14,426 & 53,753 & -1.86 & -1.13 \\
\hline Shanghai & 37,331 & 3577 & 37,933 & 3316 & 38,545 & 3073 & 3.25 & -14.09 \\
\hline Jiangsu & 58,956 & 18,412 & 62,418 & 19,356 & 66,084 & 20,349 & 12.09 & 10.52 \\
\hline Zhejiang & 44,331 & 88,722 & 45,430 & 91,686 & 46,556 & 94,749 & 5.02 & 6.79 \\
\hline Anhui & 21,614 & 122,260 & 22,297 & 123,100 & 23,002 & 123,960 & 6.42 & 1.39 \\
\hline Fujian & 16,025 & 75,993 & 17,012 & 77,181 & 18,060 & 78,387 & 12.70 & 3.15 \\
\hline Jiangxi & 8380 & 109,470 & 8325 & 109,760 & 8271 & 110,050 & -1.30 & 0.53 \\
\hline Shandong & 44,982 & 243,290 & 47,670 & 238,330 & 50,519 & 233,470 & 12.31 & -4.04 \\
\hline Henan & 27,717 & 268,320 & 29,140 & 268,060 & 30,636 & 267,800 & 10.53 & -0.19 \\
\hline Hubei & 26,430 & 147,390 & 27,373 & 148,320 & 28,350 & 149,260 & 7.26 & 1.27 \\
\hline Hunan & 22,771 & 175,740 & 24,656 & 180,200 & 26,697 & 184,780 & 17.24 & 5.14 \\
\hline Guangdong & 61,390 & 143,650 & 64,158 & 146,720 & 67,051 & 149,850 & 9.22 & 4.32 \\
\hline Guangxi & 10,395 & 115,730 & 11,253 & 116,210 & 12,183 & 116,700 & 17.20 & 0.84 \\
\hline Hainan & 3874 & 19,965 & 4094 & 20,610 & 4327 & 21,276 & 11.69 & 6.57 \\
\hline Chongqing & 14,427 & 62,013 & 15,398 & 61,826 & 16,435 & 61,639 & 13.92 & -0.60 \\
\hline Sichuan & 25,789 & 212,330 & 27,115 & 216,930 & 28,510 & 221,620 & 10.55 & 4.38 \\
\hline Guizhou & 15,788 & 90,921 & 18,324 & 93,337 & 21,266 & 95,818 & 34.70 & 5.39 \\
\hline Yunnan & 11,332 & 114,490 & 12,550 & 123,500 & 13,898 & 133,220 & 22.64 & 16.36 \\
\hline Tibet & 354 & 19,960 & 395 & 20,995 & 441 & 22,084 & 24.58 & 10.64 \\
\hline Shaanxi & 13,028 & 91,253 & 13,381 & 93,136 & 13,745 & 95,059 & 5.50 & 4.17 \\
\hline Gansu & 9973 & 65,909 & 10,512 & 67,176 & 11,080 & 68,468 & 11.10 & 3.88 \\
\hline Qinghai & 3125 & 16,196 & 3342 & 16,561 & 3575 & 16,934 & 14.40 & 4.56 \\
\hline Ningxia & 3624 & 11,980 & 4421 & 12,455 & 5393 & 12,949 & 48.81 & 8.09 \\
\hline Xinjiang & 11,110 & 53,253 & 11,562 & 54,772 & 12,032 & 56,333 & 8.30 & 5.78 \\
\hline
\end{tabular}

a SPMHCI: Staff in primary medical and health care institutions

${ }^{b}$ The eastern region includes Beijing, Tianjin, Hebei, Liaoning, Shanghai, Jiangsu, Zhejiang, Fujian, Shandong, Guangdong, and Hainan

'The middle region includes Shanxi, Jilin, Heilongjiang, Anhui, Jiangxi, Henan, Hubei, and Hunan

${ }^{\mathrm{d}}$ The western region includes Inner Mongolia, Chongqing, Guangxi, Sichuan, Guizhou, Yunnan, Tibet, Shaanxi, Gansu, Qinghai, Ningxia, and Xinjiang

The results show that the coupling degree between SPMHCI and CLS at the national, urban and rural levels were all greater than 0.98 , and the rates of change were $0.20,-0.08 \%$ and $0.86 \%$, respectively. This demonstrates that there is a strong interaction between the two systems. Improvement in CLS can convert more health-care needs into demand, increasing the efficiency, benefit, and effectiveness of SPMHCI's work. More SPMHCI, on the other hand, will help improve citizens' disease prevention, health, and labor ability, as well as reduce medical expenses and provide more income, thereby improving CLS. Although the coupling degree is very good, the CCD 
between SPMHCI and CLS in 2013-2019 was 0.56420.5775 , indicating that at present, the mutual promotion of SPMHCI and CLS has not been fully exerted.

In addition, the prediction results show that the CCD at the national level is declining but the CCD in urban and rural areas are both on an upward trend. The CCD in rural areas is higher than that in urban, which may be due to the lack of medical resources in rural areas and the greater role of SPMHCI in reducing citizen's medical expenditure and maintaining their work capacity [21, 42]. The government could fully utilize SPMHCI's role as gatekeeper in the maintenance of citizens' health, as well as increase SPMHCI's contribution to the improvement of CLS. Firstly, the government could improve its fiscal fund allocation policy and increase investment in primary medical institutions; secondly, based on the actual situation in the region, they could develop reasonable SPMHCI allocation standards and development plans, as well as take steps to meet the needs of SPMHCI training and promotion.

The Chinese government has recently attached great importance to the training and development of SPMHCI. The "China Health and Family Planning Yearbook (20142020)" shows that the number of SPMHCI increased from 3.17 million in 2013 to 3.51 million in 2019. This is a very good development. However, there were only 7.27 and 51.89 SPMHCI for every 10,000 urban and rural citizens at the end of 2019 . Additionally, about $70.21 \%$ of SPMHCI were health technical staff, which is equivalent to 5.10 and 36.43 health technical staff in primary medical and health care institutions for every 10,000 urban and rural citizens, respectively [24]. At the same time, only 37 and $15 \%$ of health technicians had a bachelor's degree or above in urban and rural primary medical and health care institutions [12]. The shortage and lower quality of SPMHCI will result in increased work pressure, lower work quality and easy job burnout [43].

Therefore, firstly, we recommend the government to continue to strengthen medical education by establishing a more reasonable and standardized system of medical student enrollment, education, and training in order to increase the overall number and level of academic qualifications of medical personnel. Secondly, it is necessary to establish and improve the work support system for SPMHCI, and guide them into the development of primary medical and health care institutions using funds and policies. In addition, since China is building medical consortia and medical communities. Medical staff of higher-level medical institutions can use "Internet +" to guide SPMHCI and provide online consultation, disease diagnosis and other services. This strategy will be able to assist SPMHCI in reducing work pressure and increasing their service delivery efficiency [1].

\section{Limitations}

Firstly, the study failed to account for the differences in service efficiency and effectiveness among SPMHCI. Secondly, due to the scarcity of data sources, this study excludes individual clinics from its primary medical and health institutions. In China, individual clinics are not one of the most important components of primary medical and health institutions, and they usually only provide services such as diagnosis of simple diseases and selling medicines. The absence of these particular clinics had no effect on the direction of the primary findings of the current study, however the precise magnitude of the impact will require more investigation once conditions permit. Finally, this study assessed the equity and CCD of SPMHCI concerning quantity and living standards of citizens. It did not attempt to assess the equity of geographical regions. When the difference in population density between regions is small, it is also worthwhile to examine the equity of SPM$\mathrm{HCI}$ across geographic regions, hence we hope in our future research to make this consideration a priority.

\section{Conclusions}

This study analyzes the current situation of the population-based Gini coefficient and the CCD between CLS for SPMHCI in China, and predicts the future development trend of equity and CCD to explore the best allocation strategy. The results showed that the number of SPMHCI in China has increased significantly, with equitable population-based allocation, and the national level of equity is better than that of urban and rural areas. At the same time, the interaction between SPMHCI and CLS is sufficient, but the degree of mutual promotion is moderate. As a result, policymakers could take targeted and effective measures to reduce health care spending, such as optimizing SPMHCI allocation and launching chronic disease management services, in order to alleviate the tension between citizens' health maintenance and living standards improvement.

\section{Abbreviations \\ CCD: Coupling coordination degree; SPMHCl: Staff in primary medical and health care institutions; GM: Grey forecasting model GM (1, 1); CLS: Citizens' living standards.}

\section{Supplementary Information}

The online version contains supplementary material available at https://doi. org/10.1186/s12939-021-01572-6.

Additional file 1:

Acknowledgments

We would like to thank the study participants and collaborators. 


\section{Authors' contributions}

JW conceived and designed this study; YM, WR, LS and ZM analyzed the data and wrote the manuscript; YM interpreted the data and policy recommendations; YM, CST, QM and JW revised the manuscript. All authors have read and approved the manuscript.

\section{Funding}

This study was funded by National Key R\&D Program of China (2018YFC0114501), 2021 Postgraduate Education Reform and Quality Improvement Project of Henan Province (YJS2021KC07), and Zhengzhou University 2020 Key Project of Discipline Construction (XKZDQY202007). The funders did not participate in study design, data collection, analysis, interpretation of data and manuscript writing.

\section{Availability of data and materials}

The data used for this manuscript from China Statistical Yearbook and China Health and Family Planning Yearbook.

\section{Declarations}

Ethics approval

Not applicable.

\section{Consent for publication}

Not applicable.

\section{Competing interests}

The authors declare that they have no competing interests.

\section{Author details}

${ }^{1}$ College of Public Health, Zhengzhou University, 100, Science Avenue, Gaoxin District, Zhengzhou 450001, Henan, China. ${ }^{2}$ Department of Health Management, Sanquan College of Xinxiang Medical University, Xinxiang 453000, Henan, China. ${ }^{3}$ Dares Salaam Institute of Technology, Department of Science and Laboratory Technology, P.O. Box 2958, Dar es Salaam, Tanzania.

Received: 25 June 2021 Accepted: 8 October 2021

Published online: 30 October 2021

\section{References}

1. Yu QQ, Yin YW, Huang DM, Sun K, Chen ZM, Guo HW, et al. Trend and equity of general practitioners'allocation in China based on the data from 2012-2017. Hum Resour Health. 2021;19:20 https://www.researchga te.net/publication/349337109_Trend_and_equity_of_general_practition ers'_allocation_in_China_based_on_the_data_from_2012-2017.

2. Jia HH, Cao P, Yu JX, Zhang JR, Jiang HR, Zhao Q, et al. A new perspective for improving the human resource development of primary medical and Health care institutions: a structural equation model study. In J Environ Res Public Health. 2021;18(5):2560 https://www.mdpi.com/1660-4601/ 18/5/2560.

3. Lu C, Zang ZX, Lan XT. Impact of China's referral reform on the equity and spatial accessibility of healthcare resources: a case study of Beijing. Soc Sci Med. 2019;235(C):1.

4. Shen X, Yang W, Sun S. Analysis of the impact of China's hierarchical medical system and online appointment diagnosis system on the sustainable development of public Health: a case study of Shanghai. Sustainability. 2019;11(23):1-26 https://econpapers.repec.org/article/gamjsusta/v_ 3a11_3ay_3a2019_3ai_3a23_3ap_3a6564-_3ad_3a289293.html.

5. Qin JM, Zang LF, Lin CM, Zhang X, Zhang YC. Scale and allocation of human resources in primary health care system in China after new medical reform. Chin Gen Pract. 2016;19(4):378-82.

6. Yang $\mathrm{QH}$. Analysis of development status of primary medical and Health institutions in Chongqing, China from 2015-2018. J Asian Res. 2020;4(4):1-9 https://www.researchgate.net/publication/346146585_ Analysis_of_Development_Status_of_Primary_Medical_and_Health_ Institutions_in_Chongqing_China_from_2015-2018.
7. The State Council of the Central People's Government of the People's Republic of China. "Healthy China 2030" Planning Outline. Beijing: Central People's Government of the People's Republic of China; 2016.

8. China National Health and Family Planning Commission. Guiding opinions on further standardizing community health service management and improving service quality. Beijing: China National Health and Family Planning Commission; 2015.

9. Li JM, Chen XL, Han XL, Zhang GH. Spatiotemporal matching between medical resources and population ageing in China from 2008 to 2017. BMC Pub Health. 2020;20:845 https://bmcpublichealth.biomedcentral. com/articles/10.1186/s12889-020-08976-z\#ref-CR9.

10. Xie X, Wu QH, Hao YH, Yin H, Fu WQ, Ning N, et al. Identifying determinants of socioeconomic inequality in health service utilization among patients with chronic non-communicable diseases in China. PLoS One. 2014;9(6):e100231 https://pubmed.ncbi.nlm.nih.gov/24960168/.

11. Zheng A, Fang Q, Zhu Y, Jiang C, Jin F, Wang X. An application of ARIMA model for predicting total health expenditure in China from 1978-2022. J Glob Health. 2020;10(1):010803 https://pubmed.ncbi.nlm. nih.gov/32257167/.

12. China National Health and Family Planning Commission. China health statistical yearbook 2020. Beijing: Peking Union Medical College Press; 2020.

13. Fu HH, Li HY. Research on equity of resource allocation of general practitioners in China based on the Theil index and grey prediction method. Health Econ Res. 2018;11:57-61.

14. Li J, Wang P, Kong X, Liang H, Zhang X, Shi L. Patient satisfaction between primary care providers and hospitals: a cross-sectional survey in Jilin province. China Int J Qual Health C. 2016;28(3):346-54 https:// pubmed.ncbi.nlm.nih.gov/27090397/.

15. Efrat S, Wong WCW, Karen K, Lona H, Michael K. Primary care priorities in addressing health equity: summary of the WONCA 2013 health equity workshop. Int J Equi health. 2014;13:104 https://link.springer. com/article/10.1186/s12939-014-0104-4.

16. Wilkinson D, Symon B. Inequitable distribution of general practitioners in Australia: estimating need through the Robin Hood index. Aust N Z J Public Health. 2010;24(1):71-5 https://pubmed.ncbi.nlm.nih.gov/10777 982/.

17. Sun WX. Research on the efficiency and equity of health resource allocation in primary medical and health institutions in Jilin Province. Jilin: Jilin University; 2020.

18. Lin CM, Zhang X, Yang XQ, Qin JM. Allocation diferences and fairness of community general practitioners in districts and counties of Beijing from 2011 to 2014. Chin Gen Pract. 2016:19(31):3781-5.

19. Okech M, Okoroafor SC, Mohammed B, Ojo O. Human resources for health coordination mechanisms: lessons from Bauchi and Cross River states of Nigeria. J Public Health. 2021;43(Supplement1):41-45.

20. Sjholm ME, Eriksson G, Bii A, Asungu J, Guidetti S. Living with consequences of stroke and risk factors for unhealthy diet- experiences among stroke survivors and caregivers in Nairobi. Kenya BMC Public Health. 2021;21(1):511.

21. Miller FA, Pascale L, Valeria RE, Jessica BP, Murray K, Stuart P. Modes of coordination for health technology adoption: Health technology assessment agencies and group procurement organizations in a polycentric regulatory regime. Soc Sci Med. 2020;265(1982):113528-9.

22. Wang W. Study on the coupling degree of my country's Health human capital investment and urbanization. China Health Eco. 2017;36(10):62-5.

23. Zhang $C$. Research on the coordinated development of basic public services and economy in Anhui Province. Changdu: Chengdu University of Technology; 2020.

24. National Bureau of Statistics of China. China Statistical Yearbook 2014-2020. [Available from: http://www.stats.gov.cn/tjsj/ndsj/].

25. China National Health and Family Planning Commission. China health statistical yearbook 2014. Beijing: Peking Union Medical College Press; 2014.

26. China National Health and Family Planning Commission. China health statistical yearbook 2015. Beijing: Peking Union Medical College Press; 2015.

27. China National Health and Family Planning Commission. China health statistical yearbook 2016. Beijing: Peking Union Medical College Press; 2016. 
28. China National Health and Family Planning Commission. China health statistical yearbook 2017. Beijing: Peking Union Medical College Press; 2017.

29. China National Health and Family Planning Commission. China health statistical yearbook 2018. Beijing: Peking Union Medical College Press; 2018.

30. China National Health and Family Planning Commission. China health statistical yearbook 2019. Beijing: Peking Union Medical College Press; 2019.

31. Pyatt G. On the interpretation and disaggregation of Gini coefficients. The Eco J. 1976;86(342):243-55 https://www.jstor.org/stable/2230745?seq=1.

32. Wang RX, Wang Y. Research on coupling and coordination between transportation fairness and regional economic development based on Gini coefficient. J of Cho Jia Uni (Soc Sci Edi). 2020;20(4):53-9.

33. Ameur AA, Sadek S. Income inequality and economic growth in Algeria: empirical study during the period 1980-2015. Man Dyn Kno Eco. 2021;9(1):39-49

34. Li JS, Sun W, Li MY, Meng LL. Coupling coordination degree of production, living and ecological spaces and its influencing factors in the Yellow River Basin. J of Cle Pro. 2021;298:126803.

35. Zou YH, Zhang YH. Analysis on the coupling coordination degree between regional economy and old-age service-a case study of Sichuan province. J of Phy: Con Ser. 1774;2021:012022 https://iopscience. iop.org/article/10.1088/1742-6596/1774/1/012022.

36. Carey D. Venue coupling and actor circulation in deliberative systems: Health care governance in Ontario. J of Del Dem. 2019;15(3):4 https:// iopscience.iop.org/article/10.1088/1742-6596/1774/1/012022.
37. Małgorzata GG, Dariusz G. Grey systems theory as an effective method for analyzing scarce, incomplete and uncertain data on the example of a survey of public perceptions of safety in urban spaces. Land. 2021;10(1):73-4 https://ideas.repec.org/a/gam/jlands/v10y2021i1p73-d480730.html.

38. Jiang N. Forecast of rural logistics talent demand in Nanling County, Wuhu City-based on the gray GM(1,1) model. Mod Bus. 2021;4:61-3.

39. Kong Y, Zou Y. The allocation and equity analysis of health human resources in Guangxi township hospitals. Chin Rur Health Sere Man. 2021;41(1):27-32.

40. Liu ZY, Dou GS, Sui MY, Ye YF. Study on the fairness of the allocation of health technicians in Shanghai community health service centers. Chin Health Res. 2020;23(1):72-7.

41. Zhu L, Zhong S, Tu W, Zheng J, He SJ, Bao JZ, et al. Assessing spatial accessibility to medical resources at the community level in Shenzhen, China Int J Env Res Pub Health. 2019;16(2):242 https://pubmed.ncbi.nlm.nih. gov/30654500/.

42. Cathy CB, Jeanette RK, Dennis DJ, Kathy SB. Palliative care practices in a rural community: cultural context and the role of community Health worker. J health care poo und. 2021;32(1):550-64.

43. Zheng YL, Yu F, Chen YL, Yu MY, Liu L, Gan Y, et al. Occupational burnout of general practitioners in China and its infuencing factors. China Gen Pract. 2019;22(7):764-9.

\section{Publisher's Note}

Springer Nature remains neutral with regard to jurisdictional claims in published maps and institutional affiliations.
Ready to submit your research? Choose BMC and benefit from:

- fast, convenient online submission

- thorough peer review by experienced researchers in your field

- rapid publication on acceptance

- support for research data, including large and complex data types

- gold Open Access which fosters wider collaboration and increased citations

- maximum visibility for your research: over $100 \mathrm{M}$ website views per year

At $\mathrm{BMC}$, research is always in progress.

Learn more biomedcentral.com/submissions 